\title{
APROXIMACIONES TEÓRICAS PARA UN DEBATE CONCEPTUAL SOBRE PARTICIPACIÓN CIUDADANÍA, DEMOCRACIA, DESCENTRALIZACIÓN, GOBERNABILIDAD, POLÍTICAS PÚBLICAS EN LOS GOBIERNOS LOCALES
}

Edgard Palazio Galo*

\begin{abstract}
Resumen
Los procesos políticos modernos traen consigo importantes debates acerca de la legitimidad de los modelos de gestión pública, los mecanismos en que se reproducen y ejecutan acciones de gobierno, la efectividad misma de dichas políticas sociales y los niveles en que los ciudadanos participan como sujetos activos en los procesos de democratización. Conceptos como gobernabilidad y gobernanza deben ser objeto de discusión propositiva en el estudio de las acciones legítimas y eficaces de gobierno. Ampliando este concepto es útil relacionarlo con gobernanza desde donde podemos explicar la capacidad de un gobierno para transformar necesidades en políticas sociales
\end{abstract}

En un nivel macro el concepto democracia evoca la idea de autogobierno presuponiendo un modelo de gobierno en la cual el poder logra estar distribuido de manera incluyente entre los miembros de la demarcación espacial determinada, ampliando de esa forma los derechos de participación efectiva. De manera que la función ideal de la democracia será producir decisiones colectivas con máximo de consenso social y mínimo de imposiciones.

Es sustantivo tener presente en la comprensión de la ciudadanía, la evolución histórica conflictiva que los mismos derechos ciudadanos han tenido a lo largo del tiempo, la trayectoria histórica de los derechos que dan origen y configuración a la ciudadanía por tanto es resultado de un múltiple proceso con consecuencias de alcances sociales o sociopolíticos, de legitimación de reivindicaciones y valores que las justifican; y político-jurídico institucional, de legalización y de nuevas políticas públicas. El estudio de la ciudadanía resulta una importante oportunidad para enfocar y restituir a la esfera social la centralidad del estudio y análisis de los sistemas sociopolíticos.

Palabras claves: participación ciudadana, gobernabilidad, políticas públicas, descentralización, democracia

Key words: citizen participation, governance, public policy, decentralization, democracy

\footnotetext{
* Doctor en Filosofía, Director Departamento Filosofía - Sociología, Coordinador Carrera Diplomacia, Ciencias Políticas/Ciencia Política y
} Relaciones Internacionales. UNAN-Managua. 


\section{Introducción}

El presente artículo aborda conceptos fundamentales en la ciencia política y trata de establecer un diálogo con los autores que sehan referidoaasunto dela gobernabilidad y gobernanza, participación ciudadana, modelos de democracia, políticas públicas, descentralización de la gestión estatal, etc. Todos ellos, conceptos válidos para ser debatidos, sobre todo en los entornos de la gestión pública y el macro contexto generado por la globalización que han derivado, según Habermas, en un déficit de legitimación democrática, pues muchas decisiones cruciales que afectan nuestras vidas escapan al control propio y son sustraídas de los ámbitos nacionales de formación de la voluntad democrática (Habermas, 2000).

En este contexto histórico social, la

participación ciudadana deja de ser sólo el problema de la estabilidad política en el corto plazo y se relaciona con la capacidad de las instituciones políticas y sociales para agregar y articular intereses a largo plazo. Siendo así, la participación ciudadana requiere el concurso de rutas que permitan satisfacer las demandas participativas, constituyendo estas demandas variables muy dinámicas en su contenido e intensidad en distintas sociedades $y$ contextos históricos.

\section{Aproximaciones teóricas Gobernabilidad}

Podemos referir, que la gobernabilidad empieza a ser abordada cuando surgen situaciones en que el entramado institucional del poder legítimo resulta no ser capaz de llevar a efecto las misiones encomendadas. Siendo la gobernabilidad objeto de reflexión y estudio en el momento que se manifiestan los límites de una acción de gobierno.
Asumimos gobernabilidad, como la cualidad propia de una comunidad política, según la cual sus instituciones de gobierno actúan eficazmente de un modo considerado legítimo por la ciudadanía, permitiendo así el libre ejercicio de la voluntad política del poder ejecutivo mediante la obediencia cívica del pueblo. De acuerdo con Arbos y Giner, en un modelo ideal suceden dos condiciones esenciales que ha de cumplir cualquier gobierno para que su existencia no sea precaria: legitimidad y eficacia. Ambas son necesarias para la estabilidad de un gobierno y el orden social. Así, gobernabilidad consiste en la capacidad de un gobierno de ejercer a la vez estas dos funciones (Arbos, Giner: 2002).

Asimismo, siguiendo a Joan Prats (2003), podemos distinguir un primer momento en que se entendió por gobernabilidad, la distancia entre demandas sociales y la habilidad del sistema institucional público, para satisfacerlas. De manera que gobernabilidad se definía en sentido amplio, como capacidad de las instituciones públicas de hacer frente a los desafíos que confrontan. De acuerdo con este autor, un segundo uso del término gobernabilidad surgiría para designar la consolidación de democracias en transición (p. 241).

De esta forma, gobernabilidad entendida como capacidad de formular e implementar, tiene una clara dimensión analítica, en cuanto examina cómo las instituciones políticas afectan la traslación de preferencias o demandas ciudadanas en políticas. En sentido normativo, gobernabilidad se asocia a mayores niveles de democracia y bienestar, por cuanto las fórmulas democráticas serán las que canalicen mejor las necesidades y demandas ciudadanas. 


\section{Gobernanza}

De acuerdo con Joan Prats (2003) puede distinguirse entre gobernanza y gobernabilidad sobre la base de la diferencia que existe entre las reglas del juego y las capacidades que confieren; siendo gobernabilidad, la capacidad de formular e implementar políticas públicas por parte de un gobierno. En esta línea, se entiende gobernanza como entramado institucional y gobernabilidad, como capacidad de gobierno conferida por dicho entramado institucional. Como derivación, podemos conceptualizar gobernabilidad y gobernanza como reglas y capacidades que representan conceptos complementarios. Advirtiendo gobernanza, como interacción entre actores estratégicos causada por la arquitectura institucional y gobernabilidad como la capacidad que dicha interacción proporciona al sistema sociopolítico para reforzarse a sí mismo.

Para mayor definición, gobernanza se establece por la interacción que forjan las reglas del juego y gobernabilidad estaría constituida por la capacidad de un sistema sociopolítico para gobernarse a sí mismo, en el contexto de otros sistemas más amplios de los que forma parte. Es la gobernanza la que determina la capacidad del gobierno para transformar necesidades en políticas, y establecer patrones de interacción entre actores estratégicos no sesgados hacia grupos de interés que permitan formulación e implementación de políticas en el menor tiempo y esfuerzo posible (Prats, 2003)

\section{Democracia}

En cambio, el concepto democracia evoca la idea de autogobierno; de libertad positiva, entendida como facultad de los individuos para participar en adopción de decisiones a las cuales que se verán sometidos. Los ejes que establecen relación vinculante, entre conceptos de democracia y ciudadanía, concurren en el pretendido de asumir que este sometimiento ciudadano se genera como resultado de presuponer la participación ciudadana en el proceso de su elaboración.

En consecuencia, es de interés asumir que la democracia en su forma de gobierno como tal, lo es, no por canalizar desde las bases su sustento político, sino por ser la forma de gobierno, en la cual el poder logra estar distribuido de manera incluyente, entre los miembros de la demarcación espacial determinada, ampliando de esa forma los derechos de participación efectiva. Se concibe la democracia en su forma elemental, como una representación de gobierno en que "el número amplio posible de individuos adultos de la colectividad participa libremente en la adopción de las decisiones colectivas a través de procedimientos establecidos como la regla de mayoría" (Salazar: 2004; 44).

En este sentido, Michelangelo Bovero (2002) afirma que,

" una forma de gobierno es democrática cuando las decisiones colectivas son el resultado de un juego político iniciado y controlado por los ciudadanos y del cual ninguno de ellos queda directamente o indirectamente excluido: los ciudadanos pueden reconocer en las decisiones públicas la expresión de una voluntad no impuesta, aun cuando no la compartan, en la medida en la que todos han participado en el proceso decisional en condiciones equitativas" ( $p$. 8).

De acuerdo con Bovero (2002), podemos asumir que la función ideal de la democracia será producir decisiones colectivas con máximo de consenso social y mínimo de imposiciones. 
Sin pretender agotarlo, un esquema de dos grupos o enfoques teóricos acerca de la democracia podrían ser, considerando lo siguiente: a) Enfoque teórico económico y elitista de democracia propuesta por Schumpeter, concibiendo a los individuos como portadores de intereses egoístas incapaces de participar en adopción de decisiones importantes de la agenda pública, según él,

"al entrar en el ámbito de la política, el ciudadano medio desciende a un escalón inferior de rendimiento mental. Razona y analiza de una forma que le parecería infantil si se tratara de la esfera de sus intereses concretos, su modo de razonar se convierte en asociativo y efectivo (...) los votantes deben respetar la división del trabajo entre ellos y los políticos a quienes han elegido. Deben comprender que, una vez que han elegido a alguien, la acción política ya no es cosa de ellos sino de este último". (Salazar: 2004; 5).

Resumiendo, para el enfoque del elitismo democrático, la vigencia de democracia se relaciona con la restricción de participación ciudadana y el imperio de racionalidad de las elites, consagradas a sí mismas con decisiones tomadas sobre la base agregada de preferencias individuales (mediante votaciones) y no sobre procesos de decisiones colectivas de carácter deliberativo.

b) Un segundo enfoque lo sustentan las teorías de democracia deliberativas, como forma de entender la democracia basada en diálogo, debate y argumentación como elementos característicos de un proceso político que busca mejorar la calidad de las decisiones colectivas de forma que el conjunto de la ciudadanía resulte beneficiado. Se espera que las decisiones resulten producto de intercambio de argumentos entre quienes participan respetando criterios de imparcialidad y racionalidad.

La perspectiva deliberativa, si bien admite pluralidad de formas de vida y existencia de diferentes preferencias políticas,

"considera que el proceso de toma colectiva de decisiones debe basarse en el intercambio de razones y argumentos hasta alcanzar un acuerdo que todos los implicados puedan aceptar. De esta forma, el objetivo de la democracia no sería tanto tomar decisiones políticas preservando las preferencias personales sino más bien alcanzar decisiones que favorezcan el bien común." (Sancho: 2003; 203)

Entre otros, los trabajos de Joshua Cohen y Jürgen Habermas pueden considerarse la base sobre la cual se ha construido el enfoque deliberativo de democracia. Para los deliberacionistas, en oposición a las tesis del elitismo, los ciudadanos están inspirados por espíritu cooperativo, actúan razonablemente y se respetan mutuamente. Habermas elaboró su modelo deliberativo de democracia a partir de la crítica a modelos normativos de democracia liberal y republicana, precisamente explicando que,

"el tercer modelo de democracia que yo quisiera proponer (el primero fue el modelo liberal y segundo el republicano) se apoya precisamente en las condiciones comunicativas bajo las cuales el proceso político tiene para sí la presunción de producir resultados racionales porque se lleva a cabo en toda su extensión de un modo deliberativo." (Habermas:1999; 9)

La democracia deliberativa, aproxima su enfoque a puntos sustantivos del debate, sobre la forma como una sociedad democrática toma decisiones colectivas de carácter vinculante: por 
agregación, negociación o discusión; el lugar espacial y temporal en donde transcurre la deliberación: foros, el espacio público o instituciones; el actor o autores que deliberan: individuo, ciudadano, agrupaciones civiles o sociales o sociedad civil; y el sentido o propósito de la deliberación; justicia o bien común.(Ortiz: 2006; 54).

Para Jon Elster (2001) democracia deliberativa tiene que ver con:

"la toma colectiva de decisiones con la participación de todos los que han de ser afectados por la decisión o por sus representantes: esta es la parte democrática (...) y la toma de decisiones por medio de argumentos ofrecidos por y para los participantes que están comprometidos con los valores de racionalidad e imparcialidad: es la parte deliberativa" (pp.13,33). Adam Przeworski (2001), por su parte, entiende por deliberación "una forma de debate cuyo objeto es cambiar las preferencias que permiten a la gente decidir como actuar" pero además es política, en tanto que "lleva a una decisión que compromete a una comunidad." (pp. 183-206)

En resumen, democracia deliberativa puede asumirse como un modelo democrático en el cual las decisiones colectivas gubernamentales deben sustentarse en la deliberación racional y pública de los individuos.

\section{Ciudadanía}

En relación con ciudadanía, la concepción moderna remitea Thomas Herbert Marshall (2004) quien imaginaba la ciudadanía como conjunto de derechos sociales, civiles y políticos que podían ser disfrutados en forma igualitaria por todos los miembros de la comunidad, percibiéndola como fuerza opuesta a la desigualdad entre las clases sociales.
Para Marshall (2004) ciudadanía civil concernía a los derechos necesarios para la libertad individual; libertad de la persona, libertad de expresión, de pensamiento y de religión, el derecho a la propiedad, a cerrar contratos válidos, y el derecho a la Justicia. Mientras que ciudadanía política, hace referencia a derechos de participar en el poder político, sea como votante o mediante la práctica política activa; y ciudadanía social se vinculaba con el derecho a gozar cierto estándar mínimo de vida y bienestar, en palabras de Marshall, derecho a un mínimo de bienestar económico y seguridad, derecho a participar del patrimonio social y a vivir la vida de un ser civilizado conforme a los estándares corrientes en la sociedad.

La trayectoria histórica de los derechos que dan origen y configuración a la ciudadanía, por tanto es el resultado de un múltiple proceso con consecuencias de alcances sociales o socio-políticos, de legitimación de reivindicaciones y valores que las justifican; y político-jurídico institucional, de legalización y de nuevas políticas públicas.

Cualquiera sea la perspectiva desde la cual se aborde, "la ciudadanía remite a un conjunto de derechos y responsabilidades de los individuos reconocidos socialmente $\mathrm{y}$ regulados por un orden institucional. En consecuencia, la ciudadanía adquiere sentido y contenido en el marco de las relaciones entre Estado y sociedad civil" (Molina: 1988; 104). Sin embargo, debemos considerar que los debates en torno a la participación ciudadana, se ha convertido en tema central para la teoría política. Hay un reconocimiento en otorgar a la noción de ciudadanía múltiples sentidos; se discute su estatus, contenido, pertenencia, vinculado a lo teórico o la práctica, su relación con el Estado y la sociedad civil. 
Es sustantivo tener presente en la comprensión de la ciudadanía, la evolución histórica conflictiva que los mismos derechos ciudadanos han tenido a lo largo del tiempo, como indica Jordi Borja (2002),

"Los derechos civiles, por ejemplo: de las mujeres, de los jóvenes, de los analfabetos, etc. se han extendido, pero todavía hoy están relativamente incompletos o insatisfechos, incluso en los países democráticos más avanzados. Los derechos políticos: el sufragio universal, la legalización de todos los partidos políticos, las autonomías territoriales, el desarrollo de la democracia participativa y deliberativa, etc., son progresos del siglo XX y están todavía incompletos". (p. 2).

Si acercamos un esquema de posibles características de la ciudadanía de nuestro tiempo, podríamos señalar sucintamente: igualdad de derechos y obligaciones, identificación o pertenecía con una comunidad política, presencia de un marco institucional y normativo que supone garantías ciudadanas y la existencia de un espacio público donde ejercitar los derechos y obligaciones que constituyen la ciudadanía.

Entonces, debemos entender su ejercicio como una acción establecida dentro de una estructura de derechos y deberes. Siendo así, participación ciudadana sería no solo un reflejo de la ciudadanía, en su aspecto puramente formal y normativo, también expresaría una condición de ciudadanía, como ejercicio constituido en la dinámica inherente del régimen político, que le sea consustancial dentro de una demarcación territorial históricamente determinada.

Concurriendo que ciudadanía es un status o sea, un reconocimiento social y jurídico, por el que una persona tiene derechos y deberes por pertenecer a una comunidad, casi siempre de base territorial y cultural. Por su parte Claudia Serrano (1988) apunta que,

"ciudadanía se refiere a la estructura de derechos y responsabilidades de las personas en su relación con el Estado y la comunidad política. La evolución de los derechos de la ciudadanía es, en gran medida, la evolución de la relación del Estado y la sociedad. Su extensión cobra sentido cuando se expresa en una estructura jurídica legal y en un conjunto de arreglos político-institucionales." (p. 5)

No obstante, es pertinente reconocer que los procesos de desarrollo de la ciudadanía son procesos conflictivos, de confrontación y diálogo social que idealmente, al final llevan a una nueva formalización política y jurídica, como adelanta Jordi Borda (2002):

"la ciudadanía es un concepto evolutivo, dialéctico: entre derechos y deberes, entre status e instituciones, entre políticas públicas e intereses corporativos o particulares. Laciudadanía es un proceso de conquista permanente de derechos formales $y$ de exigencia de políticas públicas para hacerlos efectivos." (p. 2)

Complementariamente, conviniendo con la apreciación de Natasha Molina (1988), podríamos caracterizar en una suerte de ejercicio expositivo, tres rasgos comunes al concepto moderno de ciudadanía:

"Primero, pertenencia a una comunidad de intereses o existencia de un interés general compartido y negociado desde la diversidad. La ciudadanía por tanto, supone posibilidad y libertad de acceder ese interés compartido, de hacer política en un ambiente plural. Segundo, presupone un espacio de interacción pública que puede ser más o menos complejo y diversificado en el cual sea posible poner 
en juego los derechos y por esa vía ampliar la ciudadanía. Es la parte dinámica del concepto desde la cual es posible reflexionar acerca de los actores y poderes que están en condiciones de participar e interactuar en esos espacios. Tercero, existencia de sujetos conscientes de sus derechos, activos en la vida social y política y libre para ejercerlos en condiciones de reciprocidad". (p. 105)

\section{Participación ciudadana}

El estudio de la ciudadanía, resulta una importante oportunidad para enfocar y restituir a la esfera social, la centralidad en los estudios y análisis de los sistemas sociopolíticos. El estudio de participación ciudadana se vincula con prácticas deliberativas, que tienen lugar en virtud de facultades que los dispositivos democráticos propician. Este tejido de relaciones sociales compone el medio sobre el cual se articulan diferentes formas que configuran la práctica y ejercicio de la ciudadanía, en tanto sujeta y objeto de la acción participativa.

De esta manera, cuando nos aproximamos al estudio de participación ciudadana como concepto, diferentes enfoques lo vinculan más con la práctica política que con la propia ciencia social. A veces se le relaciona con conceptos como participación política, nuevas formas de democracia, sociedad civil o capital social, entre otros. Nos adscribimos a entenderla como la forma $\mathrm{y}$ alcance en que los ciudadanos toman parte en el ciclo de las políticas públicas; diseño, implementación y evaluación más allá de posibles formas de participación vinculadas a procesos electorales.

Laparticipaciónciudadana,entendidacomo espacio de prácticas, tiene la característica de desarrollarse en mecanismos organizados por un sistema de reglas que regulan cierto tipo de acciones y relaciones sociales. La respuesta a estas cuestiones, configura las dimensiones básicas para el análisis de la participación: actores que realizan la acción participativa, modos de acción o actividades en que se concreta la participación, ámbito de actuación o nivel de producción de lo político sobre el que se ejerce y los fundamentos o valores que orientan y dan significado a la acción.

Más que un concepto, la participación ciudadana puede manejarse como conjunto de criterios que determinan el funcionamiento de un proceso, a partir de un estilo de ejercicio del gobierno que convierte la interacción y la cooperación de actores públicos y privados, en uno de sus puntales clave. Un sistema social es gobernable cuando está estructurado políticamente de modo que todos los actores estratégicos se interrelacionan para tomar decisiones colectivas y resolver sus conflictos conforme a un sistema de reglas y de procedimientos formales o informales que pueden registrarse dentro de diversos niveles de participación (Coppedege: 1996).

En términos generales, el ejercicio de la participación ciudadana se relaciona con el desarrollo de la ciudadanía. De esta forma, se comprende un ejercicio de doble vía: de la ciudadanía y de la participación ciudadana, comprendiendo que la participación tiene como punto de partida, precisamente, la ciudadanía, en tanto condición jurídica que establece, en un primer momento, "el marco de referencia formal para la participación ciudadana, y en un segundo momento, la dinámica que se produce por el vínculo entre organismos del Estado y miembros de la sociedad gobernada, como parámetro constitutivo del ejercicio efectivo de la participación". (Estella: 2005;141)

En esta línea, Bottomore nos proporciona una visión distintiva entre ciudadanía 
formal, definida como la membrecía de un Estado Nación, y ciudadanía sustantiva, que implica tener derechos y capacidad de ejercerlos, con cierto grado de participación en los ámbitos público y privado (Sojo, 2002). Lo esencial de esta contribución de Bottomore, es que rescata la centralidad de la acción social en la definición de lo que una sociedad entiende y defiende como derechos de ciudadanía en una circunstancia histórica particular.

De manera que bajo diferentes calificativos, y con diferencias sustanciales entre ellas, encontramos diversas propuestas teóricas que apuntan hacia una profundización en la democracia, en el sentido de ampliar las oportunidades de participación ciudadana: nuevas formas de democracia David Held (1996), democracia fuerte Benjamín Barber (2004), democracia deliberativa Jürgen Habermas (1989), pluralismo democrático radical Laclau y Mouffe (1987).

Asimismo, nos desmarcamos de otros conceptos que definen participación y aclaramos distinguir el concepto de participación ciudadana frente a participación social y participación comunitaria, en el sentido que la primera, tiene que ver con la intervención de los individuos organizados o no en las actividades o la esfera pública, para defender sus intereses sociales en relación más directa con el Estado. En tanto la segunda, se refiere a la capacidad de los individuos para organizarse y perseguir objetivos comunes con relaciones a otras instituciones sociales. La tercera, pertenece al ámbito no estatal, donde los individuos se organizan para el logro de determinados servicios sociales, aquellos vinculados a su vida más inmediata. Sin embargo, hay que señalar los límites entre las distintas formas de participación, en unas más que en otras, no siempre son claros. (Castro: 2002; 2)
En resumen, al definir participación ciudadana se señala que puede tener un valor sustantivo o instrumental. En el primer caso, es concebida como un valor en sí misma, en tanto supone un ejercicio de virtudes cívicas. En el segundo, se considera un medio para conseguir otros fines. Desde una perspectiva instrumental, la participación ciudadana presenta una dimensión política y otra administrativa. En la dimensión política, el objetivo principal es la democratización del sistema político, dirigida a ampliar tanto los sujetos políticos como las instancias institucionales para la participación directa en los asuntos públicos. En su dimensión administrativa, la participación ciudadana trata de aumentar la eficiencia y la calidad de la gestión pública.

El giro deseado es pasar de la política que se hace para las personas, a la política que se hace con las personas, es decir, no se trata simplemente de tener en cuenta a los afectados, sino contar con los afectados y hacerlos partícipes. La participación ciudadana se plantea, tanto en teoría como en la práctica política, como un modo de resolver o paliar aspiraciones ciudadanas, como medio para ampliar la democracia, mejorar la gestión pública o dotar de legitimidad a los mecanismos de la democracia.

De manera que debemos entender la participación ciudadana en referencia, como señala Alicia Zicardi (sd): "a las formas de inclusión de la ciudadanía en procesos decisorios. Incorporando sus intereses particulares (no individuales) respecto a determinadas temáticas" ( $\mathrm{p}$. 9). En este sentido, se presupone que a mayor nivel de inclusión ciudadana, en el ciclo de políticas públicas, se puede obtener mejores resultados que posibiliten progresar en la vía de construir ciudadanía. Se entiende pues, participación ciudadana 
como un tipo de participación colectiva y directa, que se ejerce sobre la función administrativa del sistema político; es decir, sobre la definición, elaboración, ejecución y control de las políticas públicas, a través de los cauces institucionales reconocidos por la administración.

La participación ciudadana, como intervención de los ciudadanos en la definición, elaboración y ejecución de las políticas públicas, implica necesariamente una relación con las instituciones de administración de lo público, constituye un ámbito regulado por las instituciones estatales, que establecen los canales y mecanismos, a través de los cuales ésta puede ser ejercida por los ciudadanos. (Montesinos: 2007)

Es pertinente en virtud de estas consideraciones, hablar más de participación ciudadana que de participación política, siendo que todos los ámbitos de la gestión local, requieren formas incluyentes de participación, a veces genéricas, muchas veces específicas. Esta participación puede ser información, debate, negociación, pudiendo derivar en fórmulas de cooperación, de ejecución o gestión por medio de la sociedad civil, asociaciones o colectivos, empresarios ciudadanos, organismos sindicales o profesionales, etc. (Borja: 1988; 10)

Los procesos participativos se vinculan de igual forma con la descentralización de las formas de funcionamiento y gestión de las políticas públicas. La tradición histórica en las formas de gobierno en América Latina, se ha caracterizado por un marcado centralismo, razón más que válida para otorgar sustantiva importancia a los procesos de descentralización. La idea base se deposita en la inferencia, que fortaleciendo la acción pública, se favorece la eficacia de las políticas públicas, concurriendo, la descentralización es una forma de ampliar los espacios de participación democrática de la ciudadanía y de responder mejor y más eficazmente a necesidades locales.

De tal manera, la participación ciudadana como ingrediente fundamental de gestión pública democrática, aparece como componenteesencial dela descentralización y modernización del Estado, para alcanzar objetivos fundamentales, como hacer más eficientes los servicios públicos y fortalecer la democracia por medio de una gestión pública con mayor participación.

Ballón Echegaray (2003) considera la participación ciudadana:

"como el involucramiento cotidiano y vinculante, no sólo ocasional y delegativo de los ciudadanos en los asuntos públicos; como una alternativa para responder al déficit democrático de la región e incluso como una superación de la democracia representativa. Puesto que operativamente la define como la capacidad política y jurídica de la ciudadanía de intervenir individual y colectivamente, directamente o a través de diferentes modalidades en los diversos procesos de gestión del desarrollo local especialmente aquellos que afectan las condiciones de vida materiales, sociales, políticas, económicas y culturales de la población" $(p p .4,5)$.

Como apunta Adam Przeworski (1988) las modalidades de reformas administrativas del Estado y el impulso descentralizador que conlleva, hace referencia a un tópico complejo y controversial; los argumentos en favor de la descentralización, típicamente se apoyan en la observación de que el suministro local de servicios públicos incrementa la responsabilidad 
del gobierno, al ubicarlo en la proximidad de la gente a la que sirve. Sin embargo, los argumentos en contra consideran que limita la capacidad del gobierno para reducir las disparidades locales en cuanto a los ingresos; que requiere de una mayor capacidad administrativa y que puede inducir restricciones presupuestarias que se manifiestan en que las jurisdicciones menos eficientes recibirán mayores subsidios de los gobierno centrales.

\section{Descentralización}

Las nuevas tendencias de desarrollo político, económico social y administrativo, marchan en la dirección de descentralizar al Estado en función de fortalecer el desarrollo local, asumiendo ser este espacio, el mejor escenario del ejercicio democrático. Con la descentralización del poder central del Estado, se transfiere el poder en la toma de decisiones económicas, sociales y administrativas, suponiendo mayor beneficio a políticas que fortalezcan el desarrollo local.

En este sentido, conviene definir conceptualmente lo relacionado con descentralización del Estado, asunto ampliamente debatido por corrientes de pensamiento político diverso. De acuerdo con Alfaro \& Esquivez (2002), la descentralización supone el traslado de competencias y atribuciones de un ente a otro. Con el traslado de competencias, se traslada la toma de decisiones hacia el ente objeto de la descentralización. En síntesis, se da una restructuración del poder pues se transfiere, junto con la atribución, el poder de ejecución y decisión. (Alfaro, et. al.;2002; 6)

A su vez Roy Rivera (1996), quien ha estudiado con amplitud este campo, señala que hay descentralización cuando se transfiere una competencia del aparato centralizado del Estado a los órganos sub nacionales (locales o regionales). Dotados de un mínimo de condiciones materiales, jurídicas y administrativas, les permite asumir buena parte de las funciones de gobierno o de organización de la acción estatal, en unidades territoriales que forman parte de un Estado unitario. Por desconcentración se entiende, la transferencia de una competencia a una unidad $\mathrm{u}$ órgano situado dentro del mismo sistema administrativo, por ejemplo; unidades regionales de instituciones nacionales de bienestar social, oficinas regionales de ministerios, etc. (pp. 61, 62)

De manera que el proceso de descentralización, para ser verdaderamente efectivo, implica redistribuir el poder político del Estado hacia otros órganos o instituciones estatales de carácter local. También es conveniente aclarar la relación entre un proceso de descentralización respecto a la desconcentración del Estado. En este aspecto, Rokael Cardona (2001) señala que la desconcentración del Estado “...significa en esencia que el poder central del Estado, conserva el poder y solo lo delega a determinadas dependencias del mismo órgano y a territorios determinados, evitando que otros órganos del mismo poder central del Estado o de instituciones descentralizadas y la sociedad civil, participen en su control y evaluación" ( $p$. 27).

Otra definición se aproxima más a lo que se conoce como delegación, pues esa transferencia de programas, de funciones y responsabilidades desdeel gobierno central a gobiernos regionales o funcionales, se ejecuta con el fin de mantener o implementar programas que operan fuera del control de la administración central. Pero no se transfiere la titularidad de la competencia administrativa, es decir, las decisiones serán también tomadas por el gobierno central. (Alfaro: 2002; 5) 
De tal manera que podemos entender la descentralización como política de Estado y la desconcentración como acciones de carácter administrativo dependientes de la administración central del Estado. Entendemos en resumen el proceso de descentralización como fenómeno político con amplias repercusiones de carácter administrativo, social, económico y de desarrollo de una localidad. Según Alfaro (2002), este proceso debería tener como principios rectores: Gradualidad: ser gradual y progresivo para que sea eficaz y eficiente. Además, el proceso no debe ser violento, porque la población y la entidad que es objeto de transferencias de funciones lo deben ir asimilando, viviéndolo y aprehendiéndolo. Selectividad y proporción: debe de tenerse en cuenta la capacidad de gestión de cada municipalidad para asumir funciones que se le transfieran (Alfaro: 2002; 8)

Podemos entenderquela descentralización, facilita mayor acercamiento de los ciudadanos a la toma de decisiones y por tanto estimula la participación ciudadana y su incidencia en el diseño de las políticas públicas locales. En esta línea, se espera que la participación ciudadana logre crear o promover políticas sociales identificadas con las necesidades locales.

\section{Participación ciudadana y lo local}

Una democracia participativa, es aquella que alienta en los ciudadanos la capacidad de asociarse y organizarse para incidir en la toma de decisiones públicas. De este modo, promueve la cooperación entre ciudadanos y fomenta la configuración de un círculo virtuoso, cuando se aprecian directamente las consecuencias positivas que tienen tales decisiones, en todos y cada uno de los miembros de la sociedad. La forma en que se efectúa esta participación, puede variar y es fundamental poner énfasis en promover mecanismos prácticos de participación. (Escuder \& Iglesias: s/f; 4)

En este sentido, siguiendo una lógica de profundización de la democracia, es necesario tener en cuenta dos dimensiones de la participación: a) como forma de fortalecer a la sociedad civil; y b) como medio de socialización de la política. En la primera, se pretende la redistribución del poder a favor de sujetos que históricamente han estado excluidos de su control y la autonomía de las organizaciones. En la segunda, hay un criterio de eficiencia y legitimidad de la administración pública, como nueva forma de relación entre el Estado y la sociedad, para evitar los particularismos, tanto desde el Estado como desde la sociedad civil. Se destaca que no son formas necesariamente contradictorias y que pueden ser complementarias. (Castro: 2000; 4)

Sin embargo, el tema de fondo es, cómo fomentar la participación ciudadana a nivel local. Es decir, cómo fomentar que la ciudadanía se involucre en las cuestiones que hacen a la vida pública de su comunidad. Cómo transformar a las personas en ciudadanos activos y maduros democráticamente. La participación no debe ser comprendida únicamente como la forma para facilitar la prestación de determinados servicios o legitimar determinadas decisiones, sino que debe promocionar conductas y actitudes ciudadanas activas en las resoluciones de sus problemáticas locales.

Es decir, la participación ciudadana en políticas públicas, constituye una intervención ordenada de personas y organizaciones que acuerdan afrontar los obstáculos que pudieran existir y deciden 
cooperar. De este modo, la participación se vuelve un proceso transformador que confiere otro dinamismo al sistema democrático y requiere canales de comunicación permanente entre gobernantes y gobernados. Además, tanto la oferta de espacios de participación como su demanda, desde la ciudadanía, pueden manifestarse en diferentes etapas del proceso de construcción de una política pública local. (Escuder \& Iglesias; 5)

Los gobiernos locales, constituyen la instancia de poder formal más próxima a los ciudadanos y de mayor potencial, para actuar y articular las instituciones públicas y la comunidad. En este aspecto, el nivel local parece el ámbito donde los cambios se pueden producir más claramente, y donde puede revalorizarse el papel de la participación ciudadana y el fortalecimiento de la ciudadanía. (Escuder \& Iglesias; 6)

De hecho, la tendencia en nuestros países es favorecer la participación ciudadana en el marco de procesos de descentralización del Estado. La necesidad en general no es rebatible, al reconocer ampliamente que la relación de cercanía a la cuestión públicaestatal, estimula el involucramiento ciudadano. Sin embargo, no se trata de una relación automática, no sólo porque en el ámbito local, los órganos de gobierno pueden replicar las mismas relaciones patrimoniales o clientelares que tienden a suscitar en el ámbito central, sino porque habitualmente las principales decisiones que afectan la vida local no se circunscriben a su ámbito. Por tanto, aun existiendo materias sobre qué decidir, se presentan condiciones no siempre satisfechas, dada la debilidad de muchos procesos de transferencia de competencias a lo local y sobre todo de movilización de recursos para ejercerlas, razón válida para impulsar decididamente mecanismos de participación ciudadana asociados a los procesos de descentralización. (Escuder \& Iglesias; 8)

La experiencia que en términos generales, identificó las relaciones entre ciudadanía y el Estado, como entidad representada en la estructura municipal en buena parte de la región, tuvo como característica una administración pública centralizada, reducido diseño de información y limitado acceso y participación ciudadana en la administración pública local. El diseño y funcionamiento de la administración municipal se priva del sustantivo beneficio, que podría derivar no solo de escuchar las inquietudes ciudadanas sino de acompañarse con su participación en la gestión administrativa y solución de los problemas que les afecta. (Rota: 1996)

El objetivo propuesto en la estructura y funcionamiento de la administración pública es el supuesto de propiciar, desarrollar, estimular y facilitar la participación ciudadana toda vez este ciclo contribuya efectivamente con establecer un flujo bidireccional entre ciudadanos y la administración pública cuyas funciones podemos sintetizar en proporcionar servicio, resolver problemas, satisfacer necesidades y propiciar el progreso y desarrollo. La naturaleza de tal concepción radica en lograr un cambio en la manera que se determinan las agendas públicas locales y darle protagonismo a la ciudadanía.

También es importante la consideración que hace Nuria Cunill (1995) sobre la vinculación entre participación ciudadana y democracia. Este autor ve la participación ciudadana inserta en una estrategia de democratización del Estado y aparece así como un tema relevante, "conectado con el establecimiento de instancias de mediación deliberativas y con el establecimiento 
de arenas públicas en la interfase, Estado y sociedad, capaz de movilizar espacios de representación, negociación e interlocución" (p.4).

En este marco de análisis, es necesario indagar al menos sobre tres aspectos que conciernen a la institucionalización de la articulación Estado-sociedad, mediante el fomento de la participación ciudadana, los sujetos de la participación, las modalidades que acoge y ámbitos en que se ejerce.

Para Catenazzi y Resse (200):

"este nuevo rol se basa en la premisa de que en la medida que la resolución de las cuestiones locales se acercan a la comunidad, el objetivo de alcanzar una mejor calidad de vida para la población puede transformarse en una alternativa más real de lograr, fundamentalmente por la cercanía y cotidianeidad entre autoridades y beneficiarios del territorio común. La desconcentración de funciones y responsabilidades tiene entonces como uno de sus sustentos la idea de que la identificación de problemas, las prioridades para abordarlos y la utilización de los recursos disponibles pasará a ser una tarea prioritaria del ámbito local" (p.3)

Las transformaciones estructurales, no sólo implican cambios en el aparato del Estado, también generan cambios cualitativos en la relación Estado y Sociedad, involucrando por un lado, cambios en la forma que el Estado promociona la participación ciudadana y por otro, cambio en el ejercicio mismo de la ciudadanía en los procesos de democratización. (Escobar: 2004; 98)

\section{Políticas públicas}

A Harold Lasswell (1971) se le considera el generador de esta disciplina de las políticas públicas, cuando desde los años cincuenta definió sucintamente, la política pública como: "Quién obtiene qué, cuándo y cómo", centrando este enfoque en la acción pública y su impacto en los actores beneficiados o perjudicados por esa acción. Esta propuesta empezaría a evolucionar y adquirir relevancia en el ámbito académico, intelectual y socio gubernamental hasta fines de la década de los sesenta.

Siguiendo a Aguilar Villanueva (2003), las políticas públicas son una estrategia de acción colectiva, deliberadamente diseñada y calculada en función de determinados objetivos. Implica y genera una serie de decisiones a adoptar y de acciones a efectuar, por un número extenso de actores, lo cual significa integrar la política y la gestión pública, en un curso de acción, es decir, la instrumentación de la política pública. También este autor define que: "Una política puede ser una regulación, una distribución de diversos tipos de recursos (incentivos o subsidios, en efectivo o en especie, presentes o futuros, libres o condicionados) y como una intervención redistributiva directa, más allá dejar hacer a los ciudadanos" $(1996 ; 32)$.

Marcela Noé (1998) por su parte ofrece una definición de políticas públicas asumiendo que son:

"procesos netamente políticos y no puramente una ordenación técnica de medios para el cumplimiento de metas y objetivo. En la construcción o formulación de políticas se produce un juego de poder entre múltiples actores que intentan incidir directamente o indirectamente en el curso de la formulación, implementación, ejecución y evaluación de ellas, extendiendo el campo de la acción política, más allá de la esfera estatal y de la institucionalidad formal del sector político" (p. 38). 
De igual forma, para Eugenio Lahera (2002) las políticas públicas constituyen curso de acción y flujo de información relacionada con objetivos públicos definidos de manera democrática, desarrollados por el sector gubernamental, con participación de la comunidad y del sector privado. Lahera define políticas públicas como "concatenación de actividades coherentes, por los menos en su intención y tomados principalmente por los actores del sistema público administrativo de un país, con la finalidad de resolver un problema colectivo. Estas decisiones, generan actos formalizados, de naturaleza más o menos coercitiva, con el objetivo de modificar el comportamiento de "grupos que conforman blancos", los cuales se encuentran supuestamente en el origen del problema por resolver". (Lahera: 2002; 1820).

En concreto, Eugenio Lahera (2006) platea que una política pública de excelencia corresponde a: Curso de acción y flujos de información, relacionados con un objetivo público definido en forma democrática. Estos cursos de acción y flujos de información, son desarrollados por el sector público y frecuentemente con la participación de la comunidad y el sector privado. Una política pública de calidad, contendrá orientaciones o contenidos, instrumentos o mecanismos, definiciones o modificaciones institucionales y la previsión de sus resultados. (Lahera: 2006; 2)

Se infiere de esta definición, las políticas públicas o acción pública como acciones que el sector público o entidades públicas emprenden para atender los problemas sociales, junto la participación ciudadana. En resumen, asumimos política pública como identificación por las entidades gubernamentales de un problema y su propia decisión de diseñar e implementar estrategias y acciones conjuntas con la ciudadanía para la solución equilibrada, integral y democrática de ese problema.

En general, algunas lecciones de los programas de desarrollo y políticas públicas con resultados más eficaces, han sido los que sustentan su ejecución a partir de las bases, las localidades que en su ciclo de ejecución han promovido participación en todas sus etapas, logrando por el sustento local, sostener sus acciones a más largo tiempo en la medida que la política pública satisface necesidades y expectativas de la comunidad. Condensándose para la ciudadanía, una mayor capacidad de organización y de acción, mayor control de su ejecución y desarrollo.

En Nicaragua, el esquema sustantivo de participación ciudadana, ofrece un modelo innovador y efectivo de involucramiento de los ciudadanos y los gobiernos locales en el diseño y curso de ejecución de las políticas públicas, con resultados óptimos.

De manera que estos aportes al debate, constituyen un esfuerzo sistémico desde la ciencia política por lograr articular los basamentos teóricos, desde los cuales se sustentan los enfoques presentes de los modelos de integración de la gestión pública del Estado y los agregados sinérgicos que otorgan los procesos de participación y empoderamiento ciudadano en la permanente tarea de restitución de los derechos sociales.

\section{Bibliografía}

- Arbos, Xavier \& Giner, Salvador. (2002). La gobernabilidad ciudadana y democracia en la encrucijada mundial. España. Siglo XXI.

- Aguilar Villanueva, L. (1996) El estudio de las políticas públicas. (2. Ed). 
México. Miguel A Porrúa.

- Aguilar Villanueva, L. (2003). La hechura de las políticas. (2da. Ed.) México: Miguel A. Porrúa.

- Alvarado Salas, R \& Esquivel Alfaro, J. (2002). J. VII Programa de Capacitación Municipal, Tendencias de la descentralización y el desarrollo local. Instituto de Fomento y Asesoría Municipal (IFAM).

- Ballón Echegaray, E. (2003). Desarrollo local y participación: la necesidad de problematizar el particionismo. Pobreza urbana y desarrollo, Serie Programa Frontal, (2003), 4-5.

- Borja, J. (1998). Ciudadanía y espacio público. Revista del CLAD Reforma y Democracia, (12), 10.

- Borja, J. (2002). Ciudadanía y globalización. Revista del CLAD, Reforma y Democracia,(2002), 2.

- Bovero, M. (2002). Democracia y derechos fundamentales. Isonomía, (16), 8

-Barner, B (2004). Democracia fuerte. Política participativa para una nueva época. Madrid, Almuzara.

- Catenazzi, A \& Reese, E. (2000). La construcción de estrategias de desarrollo local en las ciudades argentinas. Revista Pobreza urbana y desarrollo, planes y Programas participativos para el desarrollo local, (20) 3.

- Cardona, R (2001). Metas y desafíos de la descentralización en Guatemala. (2.ed). COMODES, Guatemala.

- Castro Suárez, R. (2000). Siete obstáculos para la participación ciudadana. El municipio de Yoro, Honduras. Democracia, derechos sociales y equidad; y Estado, política $\mathrm{y}$ conflictos sociales. CLACSO.

- Claudia S. (1998). Participación social y ciudadanía, Un debate del Chile contemporáneo. Octubre, 1998. Mideplan.

- Coppedege, M. (1996). El concepto de gobernabilidad. Modelos positivos y negativos. En; Ecuador: Un Problema de gobernabilidad. Quito, CORDESPNUD.

- Cunill Grau, N. (1995). La rearticulación de las relaciones Estado-Sociedad: en búsqueda de nuevos sentidos. Publicado en la Revista del CLAD Reforma y Democracia. (4), 4.

- Elster, J. (2001). Introducción. En, Jon, Elster. La democracia deliberativa. Barcelona, Gedisa. (pp. 13-33).

- Estella, J. (2005). Ciudadanía y participación ciudadana en la ciudad de México, UNAM. Revista América Latina Hoy, (40), 141

- Escuder, M.L. \& Iglesias, G. Participación ciudadana y democracia local: apuntes y reflexiones. Universidad de Buenos Aires - Umsam, Argentina. S/f.

- Escobar, A. (2004). Participación Ciudadana y Políticas Públicas: Una problematización cerca de la relación Estado y Sociedad Civil en América Latina en la última década. Revista Austral Ciencias Sociales, (8), 98.

- Gadea Montesinos, E. (2007). Las políticas de participación ciudadana: nuevas formas de relación entre la administración pública y la ciudadanía. El caso de la ciudad de valencia y su área metropolitana. Universitat de Valencia. Servei de Publicacions.

- Habermas, J. (1989). Teoría de la acción comunicativa. Tomo I. Taurus. Buenos Aires.

- Habermas, J. (1999). Tres modelos normativos de democracia. En, La 
inclusión del otro, Estudios de teoría política, (pp. 231-246). Barcelona: Paidos.

- Habermas, J. (2000). El Estado-nación europeo y las presiones de la globalización. New Left Review, ( ${ }^{\circ}$ $1)$.

- Held, D. (1996). Modelos de democracia. Madrid, Alianza Editorial.

- Laclau, E. \& Mouffe, CH. (1987) Hegemonía y estrategia socialista. Hacia una radicalización de la democracia. Madrid, Siglo XXI.

- Lahera Parada, E. (2000). Introducción a las políticas públicas. Santiago de Chile, Fondo de Cultura Económica.

- Lahera Parada, E. (2006). Del dicho al hecho: ¿Cómo implementar las políticas? Revista del CLAD Reforma y Democracia

- Lasswell, Harold D. (1971). A Pre-view of policy sciences. American Elsevier Publishing Co., New York.

- Marshall, T. (2004) Ciudadanía y clase social. Buenos Aires, Losada.

- Molina G, N. (1988). De la democracia a la construcción de la igualdad. Nuevas articulaciones entre ciudadanía y género. En, Enrique, Área \& Marcela, Noé.: Nociones de una ciudadanía que crece. Chile, FLACSO. (Pp.104105).

- Noé Echeverría, M. Ciudadanía y políticas públicas. En: Nociones de una ciudadanía que crece. FLACSO. Chile. 1988. p. 38.

- Oriol Prats, J. (2003). El concepto y el análisis de la gobernabilidad. Revista Instituciones y Desarrollo. (14-15), 249-245.

- Ortiz Leroux, S. (2006). Deliberando sobre la democracia deliberativa. Los dilemas de la deliberación pública.
Acta republicana política y sociedad, (5) ,54.

- Przeworski, A. (1998). Democracia y representación. CLAD, Reforma y Democracia, (1998), 21.

- Prezeworki, A. (2001). Deliberación y dominación ideológica. En, Jon Elster. La democracia deliberativa, Barcelona, Gedisa. (pp. 183-206).

- Salazar Ugarte, P. (2004). ¿Qué participación para cual democracia? En, Alicia,

- Zicardi. Participación ciudadana y políticas sociales en el ámbito local. (Instituto de Investigaciones Sociales, (p. 44). México: UNAM.

- Sancho, C. (2003). Un modelo diferente de democracia: la democracia deliberativa una Aproximación a los modelos de J. Cohen y J. Habermas. Revista de Estudios Políticos. Nueva Época, (122), 202.

- Schumpeter, J. (1968). Capitalismo, socialismo y democracia. Madrid, Aguilar. 1968.

- Sojo, C. (2002). La noción de ciudadanía en el debate latinoamericano. Revista de la CEPAL. (76), 5.

- Rivera, R. (1996). Descentralización y gestión local en América Latina. (1 ed). FLACSO, Costa Rica.

- Rota, J. (1996). Comunicación, gobierno y ciudadanía. Publicado en la Revista del CLAD Reforma y Democracia, (5).

- Ziccardi, A. Claves para el análisis de la participación ciudadana y las políticas públicas sociales del espacio local. s/d. 